\title{
Avaliação do impacto familiar em pais de crianças diagnosticadas com microcefalia pelo Zika Vírus
}

\section{Evaluation of family impact in parents of children diagnosed with microcephaly by Zika Virus}

\author{
Alyne Aparecida Ferreira Freitas' • Ivone Félix de Sousa² • Júlia da Paixão Oliveira Mello e Pargeon ${ }^{3}$

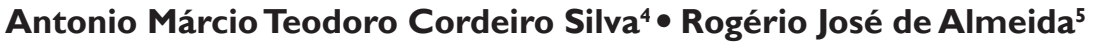

\begin{abstract}
RESUMO
Objetiva-se avaliar o impacto familiar em pais de crianças diagnosticadas com microcefalia pelo Zika vírus. Trata-se de um estudo transversal analítico com abordagem quantitativa, utilizando-se de um questionário sociodemográfico e a escala de impacto familiar (EIF). Foram pesquisados 76 pais com filhos em tratamento de reabilitação e readaptação em um centro de referência de Goiânia/GO. Foram realizadas análises descritivas utilizando-se frequência relativa e absoluta, média e desvio padrão. $O$ teste utilizado para avaliar a existência ou não de diferença estatisticamente significativa $(p \leq 0,05)$ foi a análise de variância (ANOVA) Scheffé. O pré-natal foi o período predominante do recebimento do diagnóstico de microcefalia. Foi evidenciado uma dificuldade por parte dos pais em encontrar pessoas de confiança para cuidar do filho, bem como, falta de compreensão de outras pessoas pelo fardo que é cuidar do filho deficiente. Os participantes que apresentaram maior tendência em empreender atividades com amigos, festas e bares, também se mostraram mais propensos a atividades físicas e de lazer.Após o choque inicial do recebimento do diagnóstico, os pais passam reorganizar e adaptar aos desafios, alterando a rotina familiar. É fundamental o envolvimento dos profissionais de saúde, fornecendo suporte e orientação a essas famílias.
\end{abstract}

Palavra-chave: Infecção pelo Zika vírus; Microcefalia; Saúde da Família.

\begin{abstract}
Aimed to evaluate the family impact in parents of children diagnosed with microcephaly by the Zika virus. This is a crosssectional analytical study with a quantitative approach, using a sociodemographic questionnaire and the Family Impact Scale (FIA).A total of 76 parents with children in rehabilitation and rehabilitation treatment were surveyed at a reference center in Goiânia / GO. Descriptive analyzes were performed using relative and absolute frequency, mean and standard deviation. The test used to evaluate the existence or not of a statistically significant difference $(p \leq 0.05)$ was the analysis of variance (ANOVA) Scheffé. Prenatal care was the predominant period for the diagnosis of microcephaly. It was evidenced a difficulty for the parents to find reliable people to take care of the child, as well as lack of understanding of others for the burden of caring for the disabled child. Participants who showed a greater tendency to engage in activities with friends, parties and bars were also more prone to physical and leisure activities. After the initial shock of receiving the diagnosis, the parents reorganize and adapt to the challenges, changing the family routine. The involvement of health professionals is essential, providing support and guidance to these families.
\end{abstract}

Keywords: Zika Virus infection; Microcephaly; Family health.

\section{NOTA}

'Enfermeira do Centro de Reabilitação e Readaptação Dr. Henrique Santillo, Goiânia/GO. Mestre em Ciências Ambientais e Saúde pela Pontifícia Universidade Católica de Goiás - PUC Goiás. Email: alyneferreira86@hotmail.com

${ }^{2}$ Psicóloga. Profa. Ms. do Curso de Psicologia da Pontifícia Universidade Católica de Goiás - PUC Goiás. Email: ivonefelixsousa@gmail.com

${ }^{3}$ Psicóloga. Profa. Dra. do Curso de Psicologia da Pontifícia Universidade Católica de Goiás - PUC Goiás. Email: jmellopargeon@gmail.com

${ }^{4}$ Biomédico. Prof. Dr. do Curso de Medicina e do Programa de Pós-Graduação em Ciências Ambientais e Saúde da Pontifícia Universidade Católica de Goiás - PUC Goiás. Email: marciocmed@gmail.com

${ }^{5}$ Sociólogo. Prof. Dr. do Curso de Medicina e do Programa de Pós-Graduação em Ciências Ambientais e Saúde da Pontifícia Universidade Católica de Goiás PUC Goiás. Endereço para correspondência: Av. universitária n. I440, área IV, bloco K, setor universitário. Goiânia/GO. CEP: 74605-0 I0. Email: rogeriopucgo@ gmail.com

* Freitas,AAF.Avaliação do impacto familiar em pais de crianças diagnosticadas com microcefalia pelo Zika Vírus. Dissertação de Mestrado. Goiânia/GO. Programa de Pós-Graduação em Ciências Ambientais e Saúde, Pontifícia Universidade Católica de Goiás - PUC Goiás. 2018. Os autores declaram que não há conflito de interesses. A pesquisa foi realizada com financiamento próprio. 


\section{INTRODUÇÃO}

Em 2015 houve no Brasil um crescimento de casos de crianças portadoras de microcefalia, contrastado com o histórico de quatro anos passados ${ }^{(1)}$.Antes da epidemia de Zika Vírus em 2015, os registros de microcefalia no Brasil não passavam de 150 casos por ano ${ }^{(2)}$. Em 20I6, cientistas do Centro de Controle de Doenças (CDC) de Atlanta/ EUA publicaram a certificação causal entre a microcefalia e demais lesões cerebrais e o vírus Zika ${ }^{(3-4)}$.

A proliferação descontrolada do vetor Aedes aegypti é um fato consolidado entre os brasileiros evidenciado pela constância do vírus da dengue há décadas. Esse fato contribuiu sobremaneira para a expansão de vários casos suspeitos de Zika, bem como os já confirmados.A grande questão dessa nova doença são os possíveis agravantes para a saúde humana, como o crescimento de casos de microcefalia no país e no alarmante número de casos de pacientes com a síndrome Guillain-Barré( ${ }^{(5)}$.

Nesse sentido, muitas são as expectativas e comemorações pela família acerca do nascimento de uma criança, ansiedade e dúvidas relacionadas ao futuro da criança, envolvendo sua vida e saúde. Sentimentos estes que podem ser intensificados quando os genitores recebem a notificação de seu bebê ser portador de alguma deficiência, principalmente nos dias atuais com o aumento da incidência do Zika vírus e, por consequência, dos casos de microcefalia em recém-nascidos ${ }^{(6)}$.

Existem uma variedade de fantasias que permeiam os sonhos dos genitores, considerando que nunca e nem ninguém planeja conceber um filho deficiente ${ }^{(7)}$. $O$ nascimento de um bebê com deficiência é um acontecimento ímpar na vida dos genitores que terão de lidar com a situação do filho esperado e idealizado com o filho concebido(8).

O impacto das alterações provocadas pelo diagnóstico deve ser de conhecimento dos profissionais. Desde o recebimento do diagnóstico ocorrem diversas mudanças na rotina familiar, direcionando toda a atenção para o filho doente, sendo exigidos tempo e dedicação maior nessa assistência, deixando de lado outras tarefas domiciliares como outros filhos, marido, casa, estudo e lazer ${ }^{(9)}$.

Muitas vezes o impacto familiar está representado no acúmulo de atividades e em não ter nenhuma outra pessoa que possa auxiliar na prestação de cuidados à criança deficiente, seja supervisionando esse cuidado, ou em atividades diárias e na parte financeira ${ }^{(10-1)}$.

A avaliação diagnóstica de um acontecimento único e crítico na dinâmica da família é extremamente significativa e necessita de diversas informações que sanem todos os questionamentos, inclusive o impacto desse acontecimento em âmbito familiar na perspectiva dos pais.Assim, o presente estudo teve por objetivo avaliar o impacto familiar em pais de crianças diagnosticadas com microcefalia pelo Zika vírus.

\section{MÉTODO}

Trata-se de um estudo transversal analítico com abordagem quantitativa. Este é um método de pesquisa que visa gerar informações sobre a prevalência da exposição da doença e de outras características da população. Os resultados informam, portanto, sobre a situação existente em um particular momento, o que é muito útil em planejamento de saúde ${ }^{(12)}$.

A pesquisa foi realizada por meio de questionários aplicados aos pais de crianças diagnosticadas com microcefalia, durante a realização de terapias de reabilitação, consultas e exames no Centro Estadual de Reabilitação e Readaptação Dr. Henrique Santillo (CRER) na cidade de Goiânia/GO.

O CRER é um complexo hospitalar filantrópico, sendo referência na região Centro-Oeste. Oferece serviços de reabilitação, clínica médica e clínica cirúrgica, na área de assistência à saúde, bem como incentivo em ensino e pesquisa.

Para a realização do cálculo amostral foram utilizados o número de pacientes atendidos nos últimos dois meses (janeiro e fevereiro de 2017) que antecederam a coleta de dados. Nesse período foram atendidas, dentro dos critérios de inclusão e exclusão, um total de 94 crianças. Com esta população utilizou-se um nível de confiança de $95 \%$ e margem de erro de $5 \%$, sendo a amostra final de 76 mães ou pais de crianças diagnosticadas com microcefalia que realizavam tratamento de reabilitação no CRER.

A obtenção dos consentimentos e a coleta de dados ocorreram entre os meses de março e junho de 2017. Como critérios de inclusão foram pesquisados somente os pais (mãe ou pai) de criança com diagnóstico de microcefalia, aceitação em participar da pesquisa, possuíam capacidade cognitiva para responder o questionário e idade dos pais superior a 18 anos. Como critérios de exclusão não foram considerados nesta pesquisa caso de recusa em aceitar participar da pesquisa, pais menores de idade, aqueles que manifestaram vontade em excluir seus dados no estudo e pais com diagnóstico de depressão.

Foi utilizado um questionário psicossocial ocupacional e de saúde que identificou dados como: sexo, idade, número de filhos, estado civil, situação de trabalho, renda familiar mensal, escolaridade e tipo de habitação; e questões relativas ao contexto familiar referentes ao momento da notícia e conhecimento sobre a microcefalia.

Foi utilizada a Escala de Impacto Familiar (EIF), que consiste em uma medida do impacto da doença/deficiência da criança na família, considera os efeitos que os fiIhos têm na família ao nível social, avaliando a sobrecarga (impacto familiar global) de uma forma unidimensional ${ }^{(13)}$.

Stein e Jessop, na década de 80 , desenvolveram um estudo clínico em crianças, capaz de medir o impacto fa- 
miliar e as suas repercussões ao nível da dinâmica família, através das consequências causadas por doença crônica de um filho. Inicialmente a escala era composta por 33 itens, mas estes foram reduzidos a 24 itens, devido aos casos omissos, os itens referentes ao impacto nos irmãos destas crianças $^{(13)}$.

O recurso à análise fatorial confirmatória, desenvolvida no estudo de Albuquerque et al. ${ }^{(14)}$ possibilitou a confirmação da estrutura unidimensional da EIF, sugerindo a sobrecarga relacionada à prestação de cuidados a uma criança com deficiência é um construto unidimensional, que integra a percepção de efeitos negativos no cuidador (repercussões individuais, mas também a nível familiar e social) decorrentes da prestação de cuidados $^{(14)}$.

A escala de impacto familiar utilizada neste estudo foi a versão revista, composta por 15 itens em uma escala do tipo Likert, permitindo conhecer o grau de conformidade e atitudes dos entrevistados, variando varia entre zero (discordo muito), um (discordo), dois (concordo) e três (concordo muito). Os escores foram obtidos pela soma dos 15 itens, tendo uma variação de 15 (nenhum impacto familiar) a 60 (alto impacto familiar). Quanto maior o escore, maior é a percepção de impacto familiar à condição de saúde da criança ${ }^{(14)}$.

Após a aplicação dos instrumentos de coleta, foi construído um banco de dados utilizando o software IBM SPSS Statistics 18. Por meio deste, foram realizadas análises descritivas das variáveis referentes ao tema em estudo, utilizando-se frequência absoluta $(n)$ e relativa $(\%)$, média e desvio padrão.

A normalidade dos dados foi confirmada utilizando o teste de Shapiro-Wilk. Assim, os testes utilizados para avaliar a existência ou não de diferença estatisticamente significativa $(p \leq 0,05)$ entre amostras independentes e múltiplas variáveis, foram o Teste $t$ de Student e $\circ$ teste de análise de variância (ANOVA) Scheffé, respectivamente.

A pesquisa foi registrada na Plataforma Brasil do Ministério da Saúde sob protocolo CAAE: 636473 16.6.0000.0037, aprovada pelo Comitê de Ética em Pesquisa da Pontifícia Universidade Católica de Goiás, com o parecer $\mathrm{n}^{\circ}$ I.958.307.

\section{RESULTADOS}

Responderam ao presente estudo 76 indivíduos, sendo pai ou mãe de crianças diagnosticadas com microcefalia em tratamento no CRER. Destes $89,5 \%$ eram do sexo feminino.A idade mínima foi de 18 anos e a máxima de 59 anos, sendo a média de idade de 30 anos. Relativo ao estado civil, 50 \% eram casados ou estavam em união estável, quanto a cor e etnia, predominou, com $63,2 \%$, a cor parda. Quanto à escolaridade, destacou-se $43,4 \%$ de nível médio completo, contrastando com apenas 3,9\% de indivíduos com pós-graduação.
Aproximadamente $96,1 \%$ eram praticantes religiosos, entretanto $63,2 \%$ consideravam sua fé muito forte. Sobre a renda mensal $57,9 \%$ afirmaram possuir de I a 3 salários mínimos, corroborando com $77,6 \%$ com renda família também de I a 3 salários mínimos e 30,3\% afirmaram pertencer a este núcleo familiar e sustentando quatro pessoas com tal renda. $O$ número de filhos predominou $31,6 \%$ com 2 filhos, sendo que $46,1 \%$ moram de aluguel.

Cerca de $68,4 \%$ dos entrevistados afirmaram possuir atividade de lazer e um total de $85,5 \%$ possuíam acesso à internet. Quando perguntados com que frequência vão a bares, festas e encontram amigos, $40,8 \%$ responderam "às vezes", tal qual $31,6 \%$ responderam que praticam "às vezes" atividade física. A frequência com que os entrevistados possuíam atividade de lazer foi de $32,9 \%$, respondendo como "frequentemente".

Relativo a frequência com que realizavam atividade doméstica, $60,5 \%$ responderam muito frequentemente. Cerca de $63,2 \%$ dos entrevistados negaram possuir algum problema de saúde, contudo, apenas $57,9 \%$ informaram que vão ao médico às vezes, quando passam mal. Sobre uso de medicação para tratar o problema de saúde, $63,2 \%$ negaram fazer uso. Um total de $51,3 \%$ considerou sua saúde como boa. Sobre o momento em que foi dado o diagnóstico do filho com microcefalia, $60,5 \%$ responderam que recebeu o diagnóstico ainda no pré-natal.Todos estes dados podem ser vistos na Tabela $I$.

Do ponto de vista do perfil epidemiológico dos pais entrevistados, observou-se correlação positiva identificando que quanto maior a idade do entrevistado, maior também foi a renda mensal $(r=0,246$ e $p=0,032)$, a renda familiar $(r=0,244$ e $p=0,034)$, a quantidade de pessoas que moram na mesma residência sustentadas com a renda $(r=0,433$ e $p<0,00 \mathrm{I})$ e também maior é a quantidade de filhos $(r=0,468$ e $p<0,00 \mathrm{I})$.

Dados importantes dizem respeito a utilização da renda mensal. Identificou-se que a renda mensal é inversamente relacionada com algumas atividades importantes para a família. Ou seja, quanto maior a renda mensal, menor foi a tendência dos indivíduos em frequentarem bares e encontrar amigos $(r=-0,318$ e $p=0,005)$, a praticarem atividade física $(r=-0,366$ e $p=0,00 I)$ e a fazerem atividades relacionadas ao lazer da família $(r=$ 0,518 e $p<0,001$ ).

Aqueles indivíduos cuja tendência foi de empreender atividades com amigos festas e bares se mostraram mais propensos também a praticarem atividade física $(r$ $=0,465$ e $p<0,00 I)$ e a fazerem atividade de lazer $(r$ $=0,515$ e $p<0,00 I)$. Corroborando com esses dados, identificou-se que os entrevistados que praticavam atividade física tinham uma forte tendência em terem atividades de lazer com a família $(r=0,794$ e $p<0,001)$. Os dados das correlações podem ser vistos na Tabela 2. 
TABELA 1 - Análise descritiva das variáveis psicossociais, ocupacionais e de saúde de 76 entrevistados (pais ou mães) de crianças com microcefalia atendidas em hospital de referência. Goiânia, GO, Brasil, 2017

Variáveis

Gênero

Fen

Estado Civil

\begin{tabular}{|l|l}
\hline Masculino & \\
\hline Feminino & \\
\hline Solteiro & \\
\hline Casado / União Estável & \\
\hline Viúvo & \\
\hline
\end{tabular}

Cor ou Etnia

Divorciado / Desquitado

Branca

Preta

Parda

Ensino Fundamental

Ensino Médio

Escolaridade

Ensino Superior Incompleto

Ensino Superior Completo

Pós-Graduação

Tem Religião?

Não

Sim

Você considera sua fé:

Muito Forte

Forte

Fraca

Qual sua renda mensal?

Menor que 1 salário mínimo

1 a 3 salários mínimos

Menor que 1 salário mínimo

Qual a renda familiar?

1 a 3 salários mínimos

4 a 8 salários mínimos

Duas

Três

Quantas pessoas moram com você e são sustentadas pela renda familiar?

Quatro

Cinco

Acima de Cinco

um filho

dois filhos

três filhos

Quantos filhos você tem?

quatro filhos

cinco filhos

seis filhos

Mora em casa própria - Paga

Mora em casa própria - Financ

Alugada

Cedida

Não

Vocês têm atividade de lazer?

Vocês usam a internet?

Com que frequência você vai a bares, festa e encontrar amigos?

\begin{tabular}{|l|}
\hline Sim \\
\hline Não \\
\hline Sim \\
\hline Muito frequentemente \\
\hline Frequentemente \\
\hline Às vezes \\
\hline Muito raramente \\
\hline Nunca \\
\hline
\end{tabular}

\begin{tabular}{|c|c|}
\hline $\mathrm{N}$ & $\%$ \\
\hline 8 & 10,5 \\
\hline 68 & 89,5 \\
\hline 20 & 26,3 \\
\hline 38 & 50,0 \\
\hline 4 & 5,3 \\
\hline 14 & 18,4 \\
\hline 21 & 27,6 \\
\hline 7 & 9,2 \\
\hline 48 & 63,2 \\
\hline 14 & 18,4 \\
\hline 33 & 43,4 \\
\hline 19 & 25,0 \\
\hline 7 & 9,2 \\
\hline 3 & 3,9 \\
\hline 3 & 3,9 \\
\hline 73 & 96,1 \\
\hline 48 & 63,2 \\
\hline 25 & 32,9 \\
\hline 3 & 3,9 \\
\hline 32 & 42,1 \\
\hline 44 & 57,9 \\
\hline 13 & 17,1 \\
\hline 59 & 77,6 \\
\hline 4 & 5,3 \\
\hline 2 & 2,6 \\
\hline 13 & 17,1 \\
\hline 23 & 30,3 \\
\hline 17 & 22,4 \\
\hline 21 & 27,6 \\
\hline 15 & 19,7 \\
\hline 24 & 31,6 \\
\hline 17 & 22,4 \\
\hline 11 & 14,5 \\
\hline 5 & 6,6 \\
\hline 4 & 5,3 \\
\hline 8 & 10,5 \\
\hline 16 & 21,1 \\
\hline 35 & 46,1 \\
\hline 17 & 22,4 \\
\hline 24 & 31,6 \\
\hline 52 & 68,4 \\
\hline 11 & 14,5 \\
\hline 65 & 85,5 \\
\hline 1 & 1,3 \\
\hline 20 & 26,3 \\
\hline 31 & 40,8 \\
\hline 14 & 18,4 \\
\hline 10 & 13,2 \\
\hline
\end{tabular}




\begin{tabular}{|c|c|c|c|}
\hline \multirow{5}{*}{ Com que frequência você pratica atividade física? } & Muito frequentemente & 5 & 6,6 \\
\hline & Frequentemente & 22 & 28,9 \\
\hline & Às vezes & 24 & 31,6 \\
\hline & Muito raramente & 10 & 13,2 \\
\hline & Nunca & 15 & 19,7 \\
\hline \multirow{5}{*}{ Com que frequência você tem atividade de lazer? } & Muito frequentemente & 6 & 7,9 \\
\hline & Frequentemente & 25 & 32,9 \\
\hline & Às vezes & 17 & 22,4 \\
\hline & Muito raramente & 20 & 26,3 \\
\hline & Nunca & 8 & 10,5 \\
\hline \multirow{4}{*}{$\begin{array}{l}\text { Com que frequência você realiza tarefas } \\
\text { domésticas? }\end{array}$} & Muito frequentemente & 46 & 60,5 \\
\hline & Frequentemente & 24 & 31,6 \\
\hline & Às vezes & 4 & 5,3 \\
\hline & Muito raramente & 2 & 2,6 \\
\hline \multirow{2}{*}{ Você tem algum problema de saúde? } & Não & 48 & 63,2 \\
\hline & Sim & 28 & 36,8 \\
\hline \multirow{4}{*}{ Você vai regularmente ao médico? } & Sim, 6/6 meses & 4 & 5,3 \\
\hline & Sim, 1 vez ao ano & 19 & 25,0 \\
\hline & Às vezes, quando passo mal & 44 & 57,9 \\
\hline & Nunca vou ao médico & 9 & 11,8 \\
\hline \multirow{2}{*}{$\begin{array}{l}\text { Você faz uso de alguma medicação para tratar } \\
\text { seu problema de saúde? }\end{array}$} & Sim & 28 & 36,8 \\
\hline & Não & 48 & 63,2 \\
\hline \multirow{4}{*}{ Em geral, como você diria que é sua saúde? } & Ótima & 18 & 23,7 \\
\hline & Boa & 39 & 51,3 \\
\hline & Regular & 15 & 19,7 \\
\hline & Ruim & 4 & 5,3 \\
\hline \multirow{3}{*}{$\begin{array}{l}\text { Em que momento foi dado o diagnóstico de seu } \\
\text { filho? }\end{array}$} & Na consulta pré-natal & 46 & 60,5 \\
\hline & No momento do nascimento antes da alta & 19 & 25,0 \\
\hline & Algum tempo após a alta hospitalar & 11 & 14,5 \\
\hline
\end{tabular}

fonte: dados da pesquisa

TABELA 2 - Análise de correlação de Pearson nos 76 entrevistados (pais ou mães) de crianças com microcefalia atendidas em hospital de referência. Goiânia, GO, Brasil, 2017

\begin{tabular}{|c|c|c|c|c|c|c|c|c|c|c|c|c|}
\hline Variáveis & & 1 & 2 & 3 & 4 & 5 & 6 & 7 & 8 & 9 & 10 & 11 \\
\hline \multirow[t]{2}{*}{ 1. Impacto familiar } & $r$ & 1 & & & & & & & & & & \\
\hline & $\mathrm{p}$ & & & & & & & & & & & \\
\hline \multirow[t]{2}{*}{ 2. Qual sua idade? } & $r$ & $-0,164$ & 1 & & & & & & & & & \\
\hline & $\mathrm{p}$ & 0,158 & & & & & & & & & & \\
\hline \multirow{2}{*}{ 3. Você considera sua fé: } & $r$ & 0,068 & $-0,140$ & 1 & & & & & & & & \\
\hline & $\mathrm{p}$ & 0,561 & 0,229 & & & & & & & & & \\
\hline \multirow{2}{*}{ 4. Qual sua renda mensal? } & $r$ & $-0,216$ & $0,246^{*}$ & $-0,139$ & 1 & & & & & & & \\
\hline & $\mathrm{p}$ & 0,060 & 0,032 & 0,232 & & & & & & & & \\
\hline \multirow{2}{*}{ 5. Qual a renda familiar? } & $r$ & $-0,140$ & $0,244^{*}$ & $-0,118$ & $0,303^{* *}$ & 1 & & & & & & \\
\hline & $\mathrm{p}$ & 0,228 & 0,034 & 0,309 & 0,008 & & & & & & & \\
\hline \multirow{2}{*}{$\begin{array}{l}\text { 6. Pessoas moram com você e } \\
\text { sustentadas pela renda familiar? }\end{array}$} & $r$ & $-0,023$ & $0,433^{* *}$ & $-0,166$ & 0,086 & 0,176 & 1 & & & & & \\
\hline & $\mathrm{p}$ & 0,845 & 0,000 & 0,152 & 0,459 & 0,129 & & & & & & \\
\hline \multirow[b]{2}{*}{ 7. Quantos filhos você tem? } & $r$ & $-0,125$ & $0,468^{* *}$ & $-0,075$ & 0,099 & 0,115 & $0,857^{* *}$ & 1 & & & & \\
\hline & $\mathrm{p}$ & 0,281 & 0,000 & 0,522 & 0,393 & 0,324 & 0,000 & & & & & \\
\hline \multirow{2}{*}{$\begin{array}{l}\text { 8. Com que frequência você vai a } \\
\text { bares, festa e encontrar amigos? }\end{array}$} & $r$ & $-0,146$ & $-0,062$ & 0,026 & $-0,318^{* *}$ & $-0,218$ & $-0,076$ & $-0,045$ & 1 & & & \\
\hline & $p$ & 0,207 & 0,594 & 0,826 & 0,005 & 0,059 & 0,511 & 0,702 & & & & \\
\hline
\end{tabular}




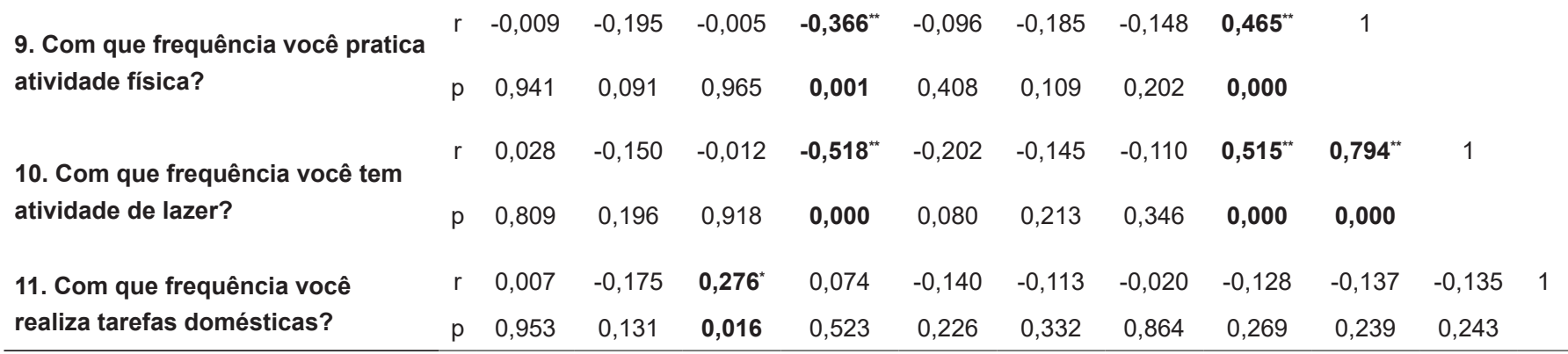

**. A correlação é significativa no nível 0,01 (2 extremidades).

*. A correlação é significativa no nível 0,05 (2 extremidades).

fonte: dados da pesquisa

$\mathrm{Na}$ análise descritiva dos itens da escala de impacto familiar, identificou-se um escore médio de $36,4( \pm 6,6)$ para impacto familiar global. Como esta se constitui em uma escala unifatorial, algumas questões em especial chamaram atenção, tendo como referência as médias de cada item da escala que varia de um a quatro. Dois itens obtiveram os escores médios mais baixos: 0 item 7 "por vezes, pergunto-me se o meu filho deveria ser tratado de forma especial ou como uma criança normal"
$(I, 8 \pm 0,8)$ e o item I 4 "ir ao hospital é uma tensão para mim" $(2,0 \pm 1,0)$.

Já os itens que apresentaram maiores escores médios foram: o item 4 "é difícil encontrar uma pessoa de confiança para cuidar do nosso filho" $(3,3 \pm 0,8)$; o item 13 "ninguém compreende o fardo que eu tenho" $(2,8 \pm 0,9)$; e o item 8 "penso em não ter mais filhos devido ao problema de saúde do meu filho" $(2,8 \pm I, 0)$. Os dados da EIF podem ser vistos na Tabela 3.

TABELA 3 - Análise descritiva da Escala de Impacto Familiar nos 76 entrevistados (pais ou mães) de crianças com microcefalia atendidas em hospital de referência. Goiânia, GO, Brasil, 2017

\begin{tabular}{|c|c|c|}
\hline Itens da Escala de Impacto Familiar & M & DP \\
\hline 1- Devido ao problema de saúde do meu filho, não podemos viajar para fora de nossa localidade. & 2,09 & 1,07 \\
\hline 2 - A pessoas na vizinhança tratam-nos de forma particular devido ao problema de saúde do nosso filho. & 2,47 & 1,00 \\
\hline 3 - Temos pouca vontade de sair devido ao problema de saúde do nosso filho. & 2,05 & 0,91 \\
\hline 4 - É difícil encontrar uma pessoa de confiança para cuidar do nosso filho. & 3,37 & 0,85 \\
\hline 5 - Por vezes temos que mudar nosso plano de sair a última hora, devido ao estado de saúde do nosso filho. & 2,70 & 0,82 \\
\hline 6 - Estamos menos vezes coma família e com os amigos devido ao problema de saúde do nosso filho. & 2,36 & 0,87 \\
\hline 7 - Por vezes, pergunto-me se o meu filho deveria ser tratado de forma "especial" ou como uma criança normal. & 1,87 & 0,84 \\
\hline 8- Penso em não ter mais filhos devido ao problema de saúde do meu filho. & 2,80 & 1,02 \\
\hline 9 - Não me sobra muito tempo para outros familiares depois de cuidar do meu filho. & 2,41 & 0,88 \\
\hline 10 - A nossa família abdica de algumas coisas devido ao problema de saúde do meu filho. & 2,64 & 0,89 \\
\hline 11 - O cansaço é um problema para mim devido ao problema de saúde no meu filho. & 2,30 & 0,86 \\
\hline 12 - Vivo um dia de cada vez e não faço planos para o futuro. & 2,05 & 0,94 \\
\hline 13 - Ninguém compreende o fardo que eu tenho. & 2,84 & 0,98 \\
\hline 14 - Ir ao hospital é uma tensão para mim. & 2,00 & 1,01 \\
\hline $\begin{array}{l}15 \text { - Por vezes, sinto que vivemos em uma montanha russa: em crise quando meu filho fica muito doente, e bem } \\
\text { quando as coisas estão estáveis. }\end{array}$ & 2,45 & 0,93 \\
\hline IMPACTO FAMILIAR GERAL & 36,41 & 6,69 \\
\hline
\end{tabular}

Fonte: dados da pesquisa 
Embora a análise dos dados estatísticos não tenha demostrado significância $(p<0,05)$, alguns indicadores são necessários apresentar a fim de melhor caracterizar as variáveis sociodemográficas em relação ao impacto familiar. Maiores escores de impacto familiar foram encon- trados na faixa etária dos 29 a 38 anos $(37,8 \pm 6,3)$, em pessoas divorciadas $(37,4 \pm 5,3)$, naqueles que informaram ter uma saúde regular $(38,2 \pm 6,7)$ e famílias com renda mensal inferior a um salário mínimo $(39,2 \pm 6,7)$. Estes dados podem ser vistos na Tabela 4.

TABELA 4 - Análise de variância (ANOVA) dos dados sociodemográficos com a Escala de Impacto Familiar nos 76 entrevistados (pais ou mães) de crianças com microcefalia atendidas em hospital de referência. Goiânia, GO, Brasil, 2017.

\begin{tabular}{|c|c|c|c|c|}
\hline Variáveis & & Impacto Familiar & & \\
\hline Idade & $\mathrm{N}$ & $(\mathrm{M} \pm \mathrm{DP})$ & $\mathbf{P}$ & \\
\hline de 18 a 28 anos & 34 & $36,2 \pm 6,7$ & & \\
\hline de 29 a 38 anos & 26 & $37,8 \pm 6,3$ & 0,30 & 0,30 \\
\hline acima de 38 anos & 16 & $36,5 \pm 7,0$ & & \\
\hline \multicolumn{5}{|l|}{ Fé } \\
\hline Muito Forte & 48 & $36,1 \pm 6,6$ & & \\
\hline Forte & 25 & $36,4 \pm 7,1$ & 0,73 & \\
\hline Fraca & 3 & $39,3 \pm 3,5$ & & \\
\hline \multicolumn{5}{|l|}{ Cor } \\
\hline Branca & 21 & $34,9 \pm 6,3$ & & \\
\hline Preta & 7 & $38,8 \pm 8,9$ & 0,37 & \\
\hline Parda & 48 & $36,6 \pm 6,4$ & & \\
\hline \multicolumn{5}{|l|}{ Estado Civil } \\
\hline Solteiro & 20 & $36,2 \pm 6,7$ & & \\
\hline Casado / União Estável & 38 & $36,5 \pm 7,1$ & 0,68 & \\
\hline Viúvo & 4 & $32,7 \pm 6,8$ & & \\
\hline Divorciado / Desquitado & 14 & $37,4 \pm 5,3$ & & \\
\hline \multicolumn{5}{|l|}{ Renda familiar } \\
\hline Menor que 1 salário mínimo & 13 & $39,2 \pm 6,7$ & & \\
\hline 1 a 3 salários mínimos & 59 & $35,7 \pm 6,6$ & 0,22 & \\
\hline 4 a 8 salários mínimos & 4 & $37,5 \pm 5,0$ & & \\
\hline \multicolumn{5}{|l|}{ Grau de Escolaridade } \\
\hline Ensino Fundamental & 14 & $36,6 \pm 7,0$ & & \\
\hline Ensino Médio & 33 & $36,2 \pm 7,0$ & & \\
\hline Ensino Superior Incompleto & 19 & $36,3 \pm 7,7$ & 0,97 & \\
\hline Ensino Superior Completo & 7 & $37,5 \pm 5,7$ & & \\
\hline Pós-Graduação & 3 & $34,3 \pm 4,0$ & & \\
\hline \multicolumn{5}{|l|}{ Quantos filhos tem } \\
\hline Um & 15 & $35,3 \pm 5,9$ & & \\
\hline Dois & 24 & $38,7 \pm 6,7$ & & \\
\hline Três & 17 & $34,9 \pm 5,0$ & 0,22 & \\
\hline Quatro & 11 & $37,6 \pm 8,6$ & & \\
\hline Cinco & 5 & $34,6 \pm 4,5$ & & \\
\hline
\end{tabular}




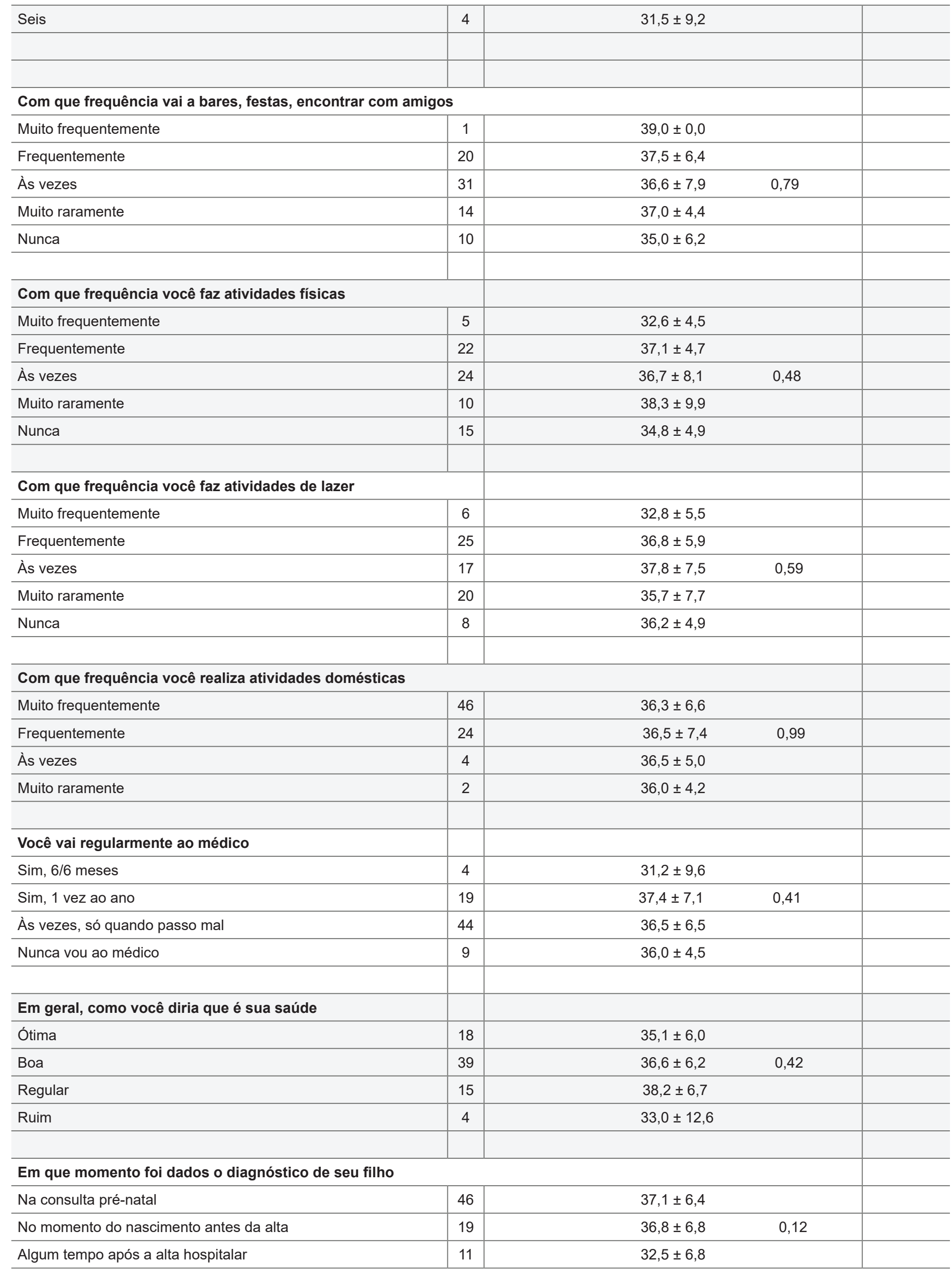

$M$, média; DP, desvio padrão

fonte: dados da pesquisa 


\section{DISCUSSÃO}

O presente estudo identificou a grande maioria de entrevistados como sendo mães, corroboram com outros achados quando evidenciado o papel da mãe como sendo a principal cuidadora. Em pesquisa sobre as circunstancias de vida de crianças portadoras de deficiência e sua relação com a instabilidade social envolvendo a rede de apoios e cuidados em saúde, obtiveram resultados similares, concluindo que os principais cuidadores eram as mães ${ }^{(15)}$. Nessa perspectiva, em outro estudo, as mães representaram em sua totalidade como cuidadoras principais, na metodologia de cuidados com a criança com doença neurológica crônica, carregando inúmeras responsabilidades e desempenhando o cuidado de forma integral ${ }^{(16)}$. Na pesquisa de Simões et al. ${ }^{(17)}$, cerca de 68 (85\%) dos participantes da amostra foi composta de mulheres cuidadoras.

Em pesquisa cujo objetivo foi avaliar o impacto do filho com microcefalia na maternagem, identificaram que tal processo é vivenciado pela mãe de maneira mais sagaz, exatamente por ela ter gerado o bebê. Constatouse as resignações de outros papéis sociais das genitoras, como a mulher do lar, esposa, profissional, mãe de outros filhos, cidadã e estudante. Muitas das mães investigadas colocaram esses papéis em segundo plano e passaram a se dedicar exclusivamente ao filho microcéfalo ${ }^{(18)}$. $\mathrm{Na}$ grande maioria das famílias, destaca-se a mulher como vital zeladora da criança, fato de que o pai já assumi a sobrecarga material em que o filho portador de doença crônica demanda ${ }^{(19)}$.

Os dados referentes à renda mensal dos entrevistados corresponderam, na maioria, entre um a três salários mínimos. Outros estudos também constataram uma renda mensal nesses parâmetros em pesquisas com pais de crianças com doenças similares à microcefalia ${ }^{(16-17)}$. A questão financeira é apontada por mães como sendo uma dificuldade ${ }^{(18)}$.

As crianças que possuem algum tipo de doença crônica, exigirá cuidados mais específicos e muitas vezes exigem constantes idas a hospitais, bem como, podem precisar de recorrentes internações hospitalares. Além do desgaste emocional e família possui custos materiais diretos, corroborando com aumento da indigência ${ }^{(19)}$.

Em um estudo com familiares de crianças portadoras de doença crônica, identificou-se que estas crianças exigiam maior capital para investimento, visto que possuíam uma série de cuidados especializados, envolvendo custo financeiro. Este estudo ainda referiu que os gastos com crianças que necessitavam de cuidados devido a sua cronicidade são três vezes maiores do que os gastos com crianças em perfeito estado de saúde.A condição de saúde crônica da criança pode demandar cerca de $40 \%$ dos recursos financeiros da família ${ }^{(20)}$.

De acordo com a grande maioria das pessoas entre- vistadas neste estudo, o diagnóstico de microcefalia foi dado ainda no período gestacional. Corroborando com esse resultado, um estudo que pesquisou a experiência parental acerca do recebimento do diagnóstico de microcefalia, evidenciou-se que o período perinatal foi $\circ$ momento mais prevalente para a revelação do diagnóstico aos pais ${ }^{(21)}$.

Uma pesquisa que investigou 22 gestantes que tiveram filhos com microcefalia em decorrência da infecção pelo Zika vírus, identificaram que 19 gestantes foram informadas sobre o diagnóstico ainda no primeiro trimestre de gestação(22). Gomes et al. ${ }^{(23)}$ também constataram o período gestacional como sendo o momento de recebimento do diagnóstico pelos pais.

No que se refere às interações sociais dos participantes deste estudo, ficou evidenciado que quanto maior a renda mensal dos entrevistados, menor foi a tendência que eles apresentaram em frequentar bares e encontrar amigos, bem como, a praticarem atividade física e a fazerem atividades relacionadas ao lazer da família.

Após o nascimento de um filho com alguma deficiência tende a ocorrer a abstenção de atividades de lazer. A privação social reflete na rotina cansativa que os pais possuem em administrar a demanda de cuidados com o filho, as idas nas terapias e consultas, bem como sua atividade laboral(20).

$O$ aspecto financeiro configura papel fundamental na vida social dos familiares da criança microcefálica. Em circunstância de fragilidade social, atinge a dinâmica familiar, ocasionando a obrigatoriedade de uma melhor administração do dinheiro, assim como, estabelecer prioridades para a destinação desse recurso que tende a ficar escasso(20).

Segundo os dados da presente pesquisa, levando em consideração o escore médio obtido para impacto familiar global, em que os participantes apresentaram maior tendência em empreender atividades com amigos, festas e bares, também se mostraram mais propensos a atividades físicas e de lazer.

Em uma pesquisa identificou-se que mesmo com os obstáculos do cotidiano, os genitores informaram que através das atividades de lazer que proporcionavam ao filho, também se beneficiavam em tais momentos, demostrando satisfação pessoal. Tais atividades abrangiam desde assistir televisão, realizar massagem e até mesmo conversar ${ }^{(17)}$. Já Salvador et al. ${ }^{(19)}$ partem do princípio que familiares que praticam atividade física, além de conseguirem fortalecimento, reduzem o estresse.

No estudo de Neves et al.(24), identificou-se como estratégia para a reconfiguração da dinâmica familiar, a criação de vínculo para o suporte social na rede institucional, tais como a comunidade, as áreas de educação e lazer, bem como no campo religioso, triando vários segmentos de saúde, em prol de tratamento adequado. 
A principal base de apoio é a família, podendo ser vista como principal unidade social a qual o indivíduo se insere e, tal como a primeira entidade que contribui para a socialização e desenvolvimento desse ser tão especial(19). Pode-se definir como rede de apoio social como sendo composta por indivíduos que possuem vínculos sociais entre si. Este apoio social engloba tanto questões informativa ou de recursos fornecidos, ocasionando efeitos emocionais, físicos e comportamentais benéficos. Os parentes se reorganizam de maneira que possam subsidiar seu familiar em grande parte de suas obrigações, afim de que, ele possa dispensar seu tempo ao cuidado à criança com doença crônica. Garantindo que estes pais se tornem mais seguros e confiantes nessa jornada ${ }^{(23)}$.

Assim, faz-se necessário a existência precisa de uma rede de apoio, permitindo a essas famílias, suporte emocional, informações diversas, bem como, proporcionar momentos de compartilhamento de experiências e vivências na prestação dos cuidados com a criança deficiente.

A assistência de enfermagem é capaz de reduzir o impacto ocasionado aos pais e familiares pela demanda de cuidados dispensados à criança com microcefalia, contribuindo para melhor funcionamento da dinâmica familiar, favorecendo tanto a vida da criança como a de seus familiares. Os profissionais da saúde devem prover ajuda através de estratégias de apoio emocional, utilizando-se da comunicação e da informação como atividades terapêuticas, corroborando no fortalecimento do vínculo familiar ${ }^{(19)}$.

É importante que o profissional estabeleça parceria com os pais, permitindo momentos de escuta e acolhida para a estruturação partilhada da assistência à criança. $A$ equipe possui o dever de capacitar a família quanto a prevenção de sequelas da microcefalia, elaborando intervenções especializadas de cuidado, tal qual, realizar observações diretas e objetivas da criança inseridas na dinâmica da família, contribuindo como fonte de suporte e afetiva de apoio a elas, minimizando os obstáculos causados pela doença ${ }^{(19)}$.

Segundo a Organização Pan Americana de Saúde (25), outro aspecto fundamental que os genitores e familiares enfrentam é a discriminação e preconceito por parte da sociedade, a equipe de profissionais de saúde são responsáveis quanto a elaboração de ações intersetoriais de saúde e de educação, levando informações à comunidade afim de, provocar mudança de comportamento, opinião e percepção, possibilitando uma alteração social favorável.

Além de toda adversidade e exaustão dos pais em se reorganizarem e conciliar a nova dinâmica familiar com a assistência dispensada ao filho microcefálico, eles ainda lidam com a exposição exagerada da mídia e comentários pejorativos. Os veículos de comunicação por meio das mídias sociais, podem fornecer informações incoerentes e incertas, com grande capacidade de atormentar e estigmatizar essas famílias ${ }^{(25)}$.
A mãe, após receber o diagnóstico de que seu filho é portador de uma doença crônica, como a microcefalia, tende a procurar e acolher diferentes formas de apoio que propiciam a sua adaptação durante esta fase inicial. Um dos apoios mais mencionados em pesquisas é a fé em Deus, por meio da espiritualidade que garante esperança e conforto para superar as adversidades geradas pelo recebimento do diagnóstico, auxiliando na aceitação da doença( ${ }^{(18-19-21)}$.

Importante salientar os resultados de que três itens da escala EIF apresentaram escores médios mais altos, demostrando áreas em que há um alto impacto familiar, são eles: é difícil encontrar uma pessoa de confiança para cuidar do nosso filho; ninguém compreende o fardo que eu tenho; e penso em não ter mais filhos devido ao problema de saúde do meu filho.

Para Beviláqua e Afonso( ${ }^{(26)}$, as doenças crônicas, por meio do sofrimento desde o nascimento até a morte do doente, podem ocasionar nos indivíduos, familiares e redes sociais rompimento de regras comuns com apoio mútuo e solidariedade.

A mãe como cuidadora principal tende a centralizar em si atividades inerentes ao lar, além de assistência ao filho deficiente. Acaba perdendo parte da sua identidade pessoal, pois o filho com doença crônica está sempre presente, por não poder contar com auxílio de terceiros no cuidado ${ }^{(27)}$. A execução dos cuidados à criança com doença crônica pode ser uma prática solitária, já que muitos compromissos se obstinam sobre a mãe, nulificada, para a maioria delas, os demais papéis que anteriormente eram exercidos como esposa, mãe de outros filhos, dona de casa, estudante e profissional ${ }^{(24)}$.

A prática experenciada pelos pais de crianças portadoras de microcefalia decorrente a infecção pelo zika vírus tem gerado alterações em suas rotinas e dinâmica familiar. Tais familiares contam com sobrecarga em todos os níveis financeiros, sociais e psicológicos relacionado aos cuidados à criança. Faz-se necessário diferentes apoios em sua trajetória, suporte social, afetivo, financeiro e principalmente apoio dos profissionais envolvidos nesse processo(21). E a enfermagem tem um papel primordial no acolhimento e assistência a essas famílias, já que o enfermeiro é um ser em movimento, capaz de imprimir algo de único nos cuidados que presta, obtendo prazer por meio do trabalho realizado ${ }^{(28)}$.

\section{CONCLUSÃO}

A epidemia da microcefalia pelo Zika vírus criou uma geração de crianças que demandará cuidados especializados ao longo de suas vidas, impactando a vida de centenas de famílias. O cenário atual exibe carência de materiais científicos envolvendo essa relação. Sabe-se que o impacto perpassa ao ambiente familiar, ocasionando 
transtornos inesperados e dificuldades para essas famílias, onde novas rotinas foram implementadas, prioridades foram levantadas e o desenvolvimento de estratégias de enfrentamento foram criadas pelos envolvidos.

Com a realização deste estudo, foi possível constatar que a mãe como principal cuidadora, sendo essas jovens com média de idade de 30 anos. $O$ recebimento da notícia que o filho possui microcefalia é um momento crítico, sendo evidenciado pela maioria dos participantes no período pré-natal. $\mathrm{Na}$ presente investigação identificou-se que os entrevistados possuíam renda mensal de um a três salários mínimos.

A dificuldade em encontrar uma pessoa de confiança para cuidar do filho deficiente, o fardo que os genitores carregam pelos filhos e o desejo em não ter mais filhos, foram fatores que apresentaram maiores escores médios de impacto familiar. Referente às interações sociais dos participantes, evidenciou-se que quanto maior a renda mensal, menor foi a tendência que eles apresentaram em frequentar bares e encontrar amigos, bem como, a praticarem atividade física e a fazerem atividades relacionadas ao lazer da família.
Ainda assim, os participantes que apresentaram maior tendência em empreender atividades com amigos, festas e bares, também se mostraram mais propensos a atividades físicas e de lazer. Percebe-se eficientes estratégias de enfrentamento quando interrogado os pais com os itens 7 e 14 da escala de impacto familiar.

Importante abordar algumas limitações da presente pesquisa que poderão comprovar certo cuidado na interpretação dos resultados. A extensão das conclusões poderá ser moderada fundamentando no tamanho da amostra. Em contrapartida, a filiação dos entrevistados por via de serviço de saúde especializado e de referência implica que estes pais contam com proveito distinto aos filhos, se equiparado aos pais que não possuem acesso a tais meios.

Assim, acredita-se ser fundamental o desenvolvimento de estudos com amostra alargadas e mais expressivas, permitindo a existência de grupo controle e grupos específicos de pais. Entretanto, mesmo com essas limitações, acredita-se que este estudo abriga informações e considerações importantes relacionadas ao impacto familiar de pais com filhos portadores de microcefalia. 


\section{REFERÊNCIAS}

I. Brito MN, Donato MAM. Vírus Zika e o sistema nervoso central: uma revisão de literatura. Cadernos de Graduação, Ciências Biológicas e de Saúde Unit. 2017;3(I):37-48.

2. Ministério da Saúde (BR). Novos casos suspeitos de microcefalia são divulgados pelo Ministério da Saúde. Brasília;2016.

3. Fauci A, Morens D. Zika Virus in the Americas - yet another arbovirus threat. N. Engl. J. Med. 2016;374(7):60I-4.

4. Morales AR, Gómez WW. El reto de Zika en Colombia y América Latina: una urgencia sanitaria internacional. Infectio. 2016;20(2):59-6I.

5. Camargo Jr KR. Zika, microcefalia, ciência e saúde coletiva. Physis. 2016;26(I):9-10.

6. Buscaglia L. Os deficientes e seus pais: um desafio ao aconselhamento. 4. ed. Rio de Janeiro: Record; 2002.

7. Glat R, Duque MAT. Convivendo com filhos especiais: o olhar paterno. Rio de Janeiro: Sete letras; 2003.

8. Henn CG, Piccinini CA, Garcias GL. A família no contexto da síndrome de Down: revisando a literatura. Psicologia em Estudo. 2008; I3(3):485-93.

9. Cunha AMFV, Blascovi-Assis SM, Fiamenghi Jr GA. Impacto da notícia da síndrome de Down para os pais: histórias de vida. Ciênc Saúde Colet. 2010;15(2):444-5I.

10. Marcon SR, Rubira EA, Espinosa MM, Barbosa DA. Qualidade de vida e sintomas depressivos entre cuidadores e dependentes de drogas. Rev. Latino-Am. Enfermagem. 20I 2;20(I):167-74.

II. Silva CF, Passos VMA, Barreto SM. Frequência e repercussão da sobrecarga de cuidadoras familiares de idosos com demência. Rev. bras. geriatr. gerontol. 20I2;15(4):707-3I.

12. Pereira MG. Epidemiologia: teoria e prática. Rio de Janeiro: Guanabara Koogan; 2005.

13. Stein RE, Jessop DJ. The impact on family scale revisited: further psychometric data.J Dev Behav Pediatr. 2003;24(I):9-16.

14. Albuquerque S, Fonseca A, Pereira M, Canavarro MC. Estudos psicométricos da versão portuguesa da Escala de Impacto Familiar (EIF). Laboratório de Psicologia. 20। I;9(2): 175-89.

15. Rezende JMM, Cabral I. E. As condições de vida das crianças com necessidades especiais de saúde: determinantes da vulnerabilidade social na rede de cuidados em saúde as crianças com necessidades especiais de saúde. Revista
Pesquisa Cuidado Fundamental. 2010;2:22-5.

16. Gondim KM, Carvalho ZMF.Sentimentos das mães de crianças com paralisia cerebral à luz da teoria de Mishel. Esc. Anna Nery. 2012;16(I):II-6.

17. Simões CC, Silva L, Santos MR, Misko MD, Bousso RS. A experiência dos pais no cuidado dos filhos com paralisia cerebral. Rev. Eletr. Enf. 20I3;15(I):138-45.

18. Santos JHA, Farias AM. "Ela vale por cinco crianças": o impacto da microcefalia na maternagem. Anais do Conbracis. 2017.

19. SALVADOR, M. S. et. al. Estratégias de famílias no cuidado a criança portadoras de doenças crônicas. Texto contexto Enferm. 20I5;24(3):662-9.

20. Baltor MRR, Dupas G. Experiências de famílias de crianças com paralisia cerebral em contexto de vulnerabilidade social. Rev. Latino-Am. Enfermagem. 20 I3;2I (4): I-8.

21. Oliveira MC, Sá SM. A experiência parental após o diagnóstico da microcefalia por zika vírus: um estudo de caso. Revista Pesquisa em Fisioterapia. 2017;7(4):64-70.

22. Flor CJDRV, Guerreiro CF, Anjos JLM. Desenvolvimento neuropsicomotor em crianças com microcefalia associado ao Zika Vírus. Revista Pesquisa em Fisioterapia. 2017;7(3):313-8.

23. Gomes GC, Pintanel AC, Strasburg AC, Erdmann AL. O apoio social ao familiar cuidador durante a internação hospitalar da criança. Rev Enferm UERJ. 201 I; I9(I):64-9.

24. Neves ET, Silveira A, Arrué AM, Pieszak GM, Zamberlan KC, Santos RP. Rede de cuidados de crianças com necessidades especiais de saúde. Texto contexto - Enferm. 2015;24(2):399-406.

25. Pan American Health Organization. Zika virus infection: step by step guide on Risk Communication and Community Engagement. Washington: OPAS; 2017.

26. Beviláqua $S$, Afonso C. Narrativas da experiência de pais de crianças com fibrose cística. Interface: Comunicação, Saúde e Educação. 2015; 19(55): 1077-88.

27. Mello DF, Lima RAG, Scochi CGS. Health follow-up of children in poverty situation: between the routine and eventuality of daily care. Rev. Latino-Am. Enfermagem. 2007;15:820-27.

28. Sousa MMT, Passos JP. O trabalho do enfermeiro no contexto hospitalar sob a perspectiva da clínica da atividade: nota previa. Rev. Enfermagem Atual. 2018;84(22): 195- 198. 